\title{
Plasma resistin, adiponectin and leptin levels in lean and obese subjects: correlations with insulin resistance
}

\author{
Josef V Silha ${ }^{1}$, Michal Krsek ${ }^{2}$, Jan V Skrha ${ }^{2}$, Petr Sucharda ${ }^{2}$, B L G Nyomba ${ }^{3}$ and Liam J Murphy ${ }^{1,3}$ \\ Departments of ${ }^{1}$ Physiology and ${ }^{3}$ Internal Medicine, University of Manitoba, Winnipeg, Canada and ${ }^{2}$ Third Department of Internal Medicine, \\ First Faculty of Medicine, Charles University, Prague, Czech Republic
}

(Correspondence should be addressed to L J Murphy, Room 843, John Buhler Research Center, University of Manitoba, 715 McDermot Avenue, Winnipeg, Manitoba R3E 3P4, Canada; Email: ljmurph@cc.umanitoba.ca)

\begin{abstract}
Objective: Adipose tissue regulates insulin sensitivity via the circulating adipocytokines, leptin, resistin and adiponectin. The objective of this study was to compare the levels of resistin, adiponectin and leptin in lean and obese subjects and determine the relationship between circulating adipocytokines and insulin resistance.

Methods: We examined plasma levels of resistin, adiponectin and leptin in 17 lean subjects with a mean body mass index (BMI) of $\sim 23$ and 34 non-diabetic obese individuals with a mean BMI $\sim 33$. Insulin resistance was assessed using the homeostasis model assessment ratio (HOMA-R) formula derived from fasting insulin and glucose levels.

Results: Resistin levels were not significantly different between the two groups but were significantly higher in women compared with men, $35.4 \pm 6.5$ (s.E.) vs $15.4 \pm 2.9 \mu \mathrm{g} / \mathrm{l}, P<0.01$. Resistin did not correlate with BMI but did significantly correlate with HOMA-R, $P<0.01$, and this correlation remained significant after adjustment for gender and BMI. Adiponectin levels were significantly lower in obese compared with lean subjects, $P<0.005$, and higher in women, $P<0.001$, but showed no significant correlation with HOMA-R. Leptin levels were significantly higher in obese subjects and women and correlated with HOMA-R and resistin.

Discussion: In this small group of patients we demonstrated that insulin resistance correlated most strongly with leptin levels. A significant correlation between resistin levels and insulin resistance was also observed. Although a similar trend was apparent for adiponectin, the correlation with insulin resistance did not achieve statistical significance.
\end{abstract}

European Journal of Endocrinology 149 331-335

\section{Introduction}

While it has long been apparent that obesity is a major risk factor for type 2 diabetes, it has recently been appreciated that adipose tissue, in addition to its role as an energy reservoir, modulates energy metabolism via secretion of circulating adipocytokines. Of adipocytokines recently identified, resistin and adiponectin appear to be important in regulating insulin sensitivity. Although obesity, particularly visceral obesity, is associated with insulin resistance (1), the mechanism whereby adipose tissue modulates insulin sensitivity is controversial.

Resistin and adiponectin have been identified as having differing effects on insulin sensitivity. Resistin is a peptide hormone produced by mature adipocytes and regulates whole-body insulin sensitivity (2). It is more highly expressed in visceral white fat than in subcutaneous fat (2). It was initially isolated as an mRNA whose expression is suppressed in response to rosiglitazone, a peroxisome proliferator-activated receptor- $\gamma$
(PPAR- $\gamma$ ) agonist that enhances insulin sensitivity $(2,3)$.

Apronectin is an adipocyte-specific, secreted protein that sensitizes the liver and muscle to the action of insulin (4). Adiponectin expression and levels in the circulation are upregulated by the PPAR- $\gamma$ agonist, rosiglitazone (5). Leptin is yet another adipocytokine that has been implicated in glucose homeostasis. It is thought to have some role in regulating insulin sensitivity $(6,7)$.

To investigate the relative role of these adipocytokines in the insulin resistance of obesity we compared the levels of resistin, adiponectin and leptin in lean and obese subjects.

\section{Subjects and methods}

\section{Subjects}

Both lean and obese male and female Caucasian subjects were studied. Participants in the study were recruited from healthy volunteers and patients 
attending obesity clinics at either institution. Informed consent was obtained from all subjects. The study protocol was approved by the Research Ethics Committees of both institutions. Subjects were considered lean if their body mass index (BMI) was less than 25. Obese subjects were screened for diabetes using an oral glucose tolerance test. The WHO diagnostic criteria were used to interpret the oral glucose tolerance test. Subjects found to have diabetes were excluded.

\section{Assays}

Resistin was measured by an enzyme-linked immunoassay kit obtained from Biovendor Laboratory Medicine Inc. (Brno, Czech Republic). This biotin-labeled antibody sandwich assay measures homodimeric resistin. The intra-assay and interassay coefficients of variation were 4.5 and $7.8 \%$. Adiponectin, leptin and insulin were measured by RIA using reagents from Linco Research Inc. (St Charles, MO, USA) and PharmaciaUpjohn Diagnostics (Uppsala, Sweden) respectively. Samples were measured in duplicate in the same assay run where the intra-assay coefficients of variation were 5, 4.5 and $6 \%$ respectively. The insulin RIA measures immunoreactive insulin since the antibody used shows some cross-reaction with proinsulin and incompletely cleaved proinsulin. Blood glucose was measured using an automated glucose oxidase method. Insulin resistance was assessed using the homeostasis model assessment ratio (HOMA-R) formula (8).

\section{Statistical analysis}

Data are expressed as means \pm s.E. Statistical analysis was performed using either a two-tailed Student's $t$-test where single comparisons were made or a Dunnett $t$-test where multiple comparison with one control group was required (as in Fig. 2). Linear regression analysis was used to determine correlation coefficients between various parameters. Prior to regression analysis, data were tested for normality of distribution by the Shapiro-Wilk test and consequently BMI, HOMA-R, leptin, insulin, resistin and adiponectin were log transformed to obtain normal distributions. Partial correlation coefficients were also obtained by controlling for gender, BMI and fasting glucose.

\section{Results}

The mean fasting plasma glucose level was significantly higher in the obese subjects than in the lean subjects but still within the normal non-diabetic range (Table 1). Five obese patients had impaired fasting glucose $(6.1-7.0 \mathrm{mmol} / \mathrm{l})$, while no lean subjects had impaired fasting glucose. Insulin levels and insulin resistance, as assessed using the HOMA-R formula, were significantly increased in obese subjects compared with lean controls (Table 1).
Plasma resistin levels were similar in lean and obese subjects. However, like adiponectin and leptin, resistin levels were significantly higher in women compared with men; $35.4 \pm 6.5$ vs $15.4 \pm 2.9 \mu \mathrm{g} / \mathrm{l}, \quad P<0.01$. Resistin did not correlate with BMI but did significantly correlate with HOMA-R, $P<0.01$ (Fig. 1). This correlation remained significant even after adjustment for gender, and for gender and BMI (Table 2).

Adiponectin levels were significantly lower in obese compared with lean subjects (Table 1). Adiponectin levels were higher in lean women compared with lean men, $17.6 \pm 2.0$ vs $7.0 \pm 0.7 \mathrm{mg} / \mathrm{l}, P<0.005$, but no significant gender difference was apparent in obese subjects $(9.8 \pm 1.1$ vs $7.1 \pm 0.7 \mathrm{mg} / \mathrm{l}$ for women and men respectively). Adiponectin levels showed no significant correlation with HOMA-R (Table 2).

Leptin levels were significantly higher in obese subjects (Table 1) and women. Leptin levels were correlated significantly with BMI, $R=0.732, P<0.001$, and HOMA-R. The correlation between leptin and HOMA-R remained significant even after adjusting for gender, and gender and BMI (Table 2). A significant correlation was observed between leptin and resistin, whereas there was no significant correlation between adiponectin and either leptin or resistin.

Since HOMA-R is not a particularly precise measure of insulin resistance we also analyzed the correlation between the adipocytokine levels and fasting glucose and insulin separately. Fig. 2 shows the relationship between fasting glucose and adipocytokine levels. Subjects with fasting glucose in the lowest and highest tertiles had similar adiponectin levels, whereas subjects who were in the highest tertile group for fasting glucose had significantly higher resistin and leptin levels than those in the lowest tertile for fasting glucose. Resistin and leptin significantly correlated with fasting insulin levels even after controlling for fasting glucose, gender, and gender and BMI (Table 3).

\section{Discussion}

In this study we report for the first time resistin levels in normal men and women. There was a significant gender difference, with women having higher values

Table 1 Description of study population.

\begin{tabular}{lccc}
\hline & Lean subjects & Obese subjects & $\boldsymbol{P}$ value \\
\hline Males/females & $7 / 10$ & $16 / 18$ & $\mathrm{NS}$ \\
Age (years) & $46.6 \pm 1.2$ & $45.2 \pm 1.0$ & $\mathrm{NS}$ \\
$\mathrm{BMI}\left(\mathrm{kg} / \mathrm{m}^{2}\right)$ & $23.1 \pm 0.4$ & $33.0 \pm 1.3$ & $<0.001$ \\
Insulin $(\mathrm{mU} / \mathrm{l})$ & $5.6 \pm 0.6$ & $11.7 \pm 1.0$ & $<0.001$ \\
Glucose $(\mathrm{mmol} / \mathrm{l})$ & $4.6 \pm 0.2$ & $5.1 \pm 0.1$ & $<0.05$ \\
HOMA-R & $1.2 \pm 0.2$ & $2.8 \pm 0.3$ & $<0.001$ \\
Resistin $(\mu \mathrm{g} / \mathrm{l})$ & $21.5 \pm 3.2$ & $28.8 \pm 5.8$ & $\mathrm{NS}$ \\
Adiponectin $(\mathrm{mg} / \mathrm{l})$ & $13.3 \pm 1.8$ & $8.6 \pm 0.8$ & $<0.005$ \\
Leptin $(\mu \mathrm{g} / \mathrm{l})$ & $5.9 \pm 0.7$ & $26.9 \pm 3.9$ & $<0.001$ \\
\hline
\end{tabular}

NS, not significant. 


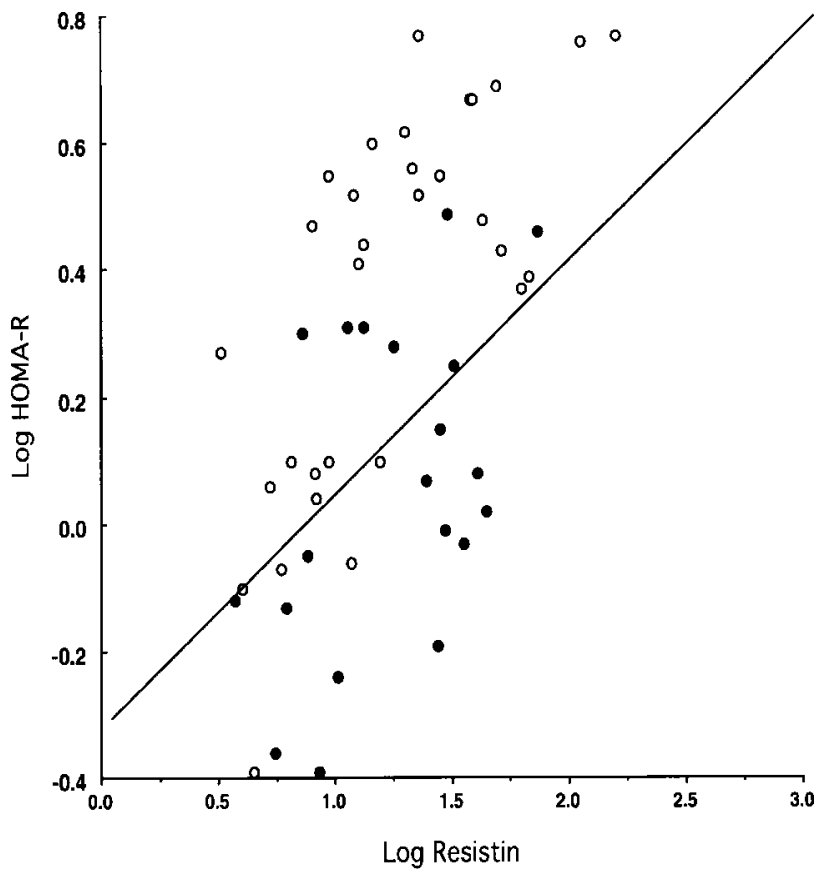

Figure 1 Correlation between log-transformed plasma resistin and log HOMA-R. Open circles indicate the obese subjects while closed circles represent the lean subjects. The line of best fit is indicated.

Table 2 Correlations between adipocytokines and HOMA-R.

\begin{tabular}{llll}
\hline & Resistin & Adiponectin & Leptin \\
\hline Unadjusted & $R=0.564$ & $R=0.055$ & $R=0.841$ \\
& $P<0.001$ & $P=0.702$ & $P<0.001$ \\
Adjusted for gender & $R=0.490$ & $R=-0.140$ & $R=0.806$ \\
& $P<0.001$ & $P=0.331$ & $P<0.001$ \\
Adjusted for gender & $R=0.513$ & $R=-0.105$ & $R=0.608$ \\
and BMl & $P<0.001$ & $P=0.478$ & $P<0.001$ \\
\hline
\end{tabular}

than men. Resistin levels were similar in lean and obese subjects and no significant correlation was observed between resistin levels and BMI. Despite these observations there was a significant correlation between resistin level and insulin resistance as measured by the HOMA-R technique. This correlation was observed even after correcting for gender and BMI. HOMA-R is a relatively imprecise method of measuring insulin resistance compared with the glucose clamp technique. The RIA used to measure insulin may measure proinsulin and partially cleaved proinsulin molecules that may be more abundant in insulin-resistant subjects. However, despite these potential limitations, a significant correlation was observed between fasting insulin levels and resistin and between fasting insulin and leptin levels. In contrast, adiponectin levels did not correlate with HOMA-R or fasting insulin.

Resistin is a peptide hormone produced by adipocytes $(9,10)$ and regulates insulin sensitivity $(2)$. It is more highly expressed in omental and abdominal subcutaneous white fat than in adipose tissue from the thigh or breast (9). It was initially isolated as an mRNA whose expression is suppressed in response to rosiglitazone (2). Rosiglitazone, a PPAR- $\gamma$ receptor agonist, enhances insulin sensitivity and this effect may be due in part to suppression of resistin expression. Furthermore, non-coding single-nucleotide polymorphisms in the resistin gene have been associated with both type 2 diabetes and obesity in Caucasian populations $(11,12)$.

As previously reported by others, adiponectin levels were reduced in obese subjects and increased in women compared with men (13-16). Although other investigators have reported significant correlations between adiponectin levels and insulin resistance in larger studies $(13,16)$, no significant correlation was demonstrated in our subjects. Unlike resistin and
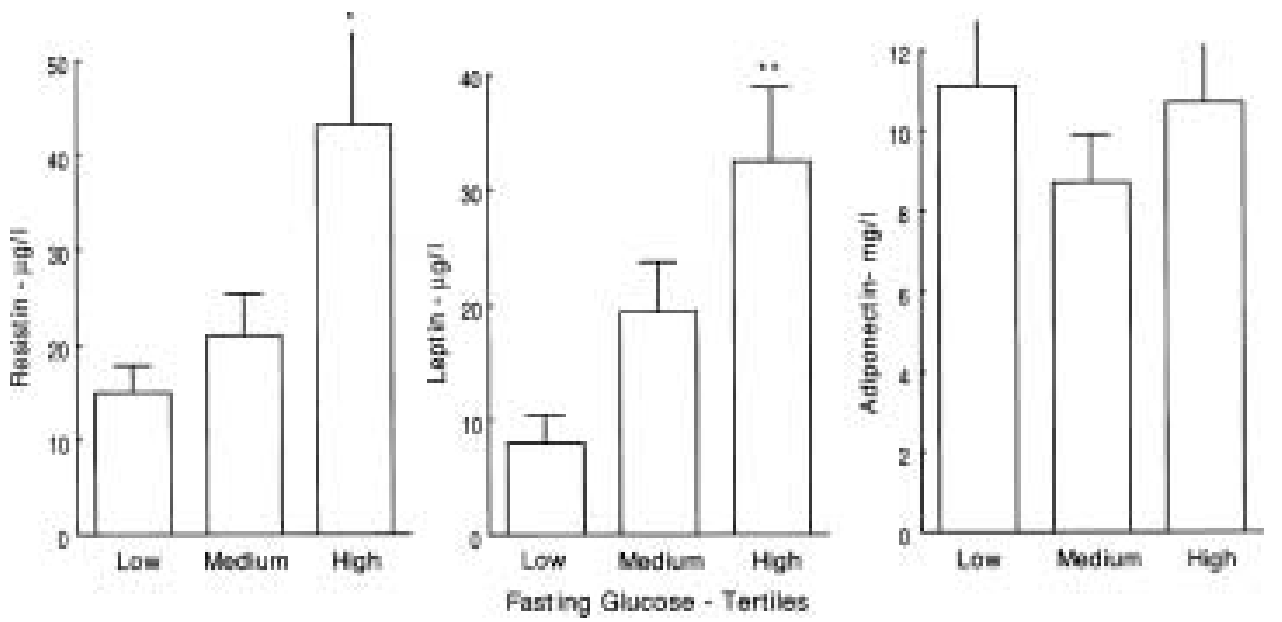

Figure 2 Distribution of adipocytokine levels according to fasting glucose. Lean and obese subjects were divided into tertiles based upon fasting glucose levels. ${ }^{\star} P<0.05,{ }^{\star} * P<0.01$ for the significance of the difference between the highest and lowest tertile of fasting glucose. The glucose ranges for the tertiles were $3.1-4.7,4.70-5.2$ and $5.2-6.4 \mathrm{mmol} / \mathrm{l}$ respectively. 
Table 3 Correlations between adipocytokines and fasting insulin.

\begin{tabular}{llll}
\hline & Resistin & Adiponectin & Leptin \\
\hline Unadjusted & $R=0.547$ & $R=0.059$ & $R=0.880$ \\
& $P<0.001$ & $P=0.683$ & $P<0.001$ \\
Adjusted for fasting glucose & $R=0.364$ & $R=-0.132$ & $R=0.873$ \\
& $P=0.009$ & $P=0.360$ & $P<0.001$ \\
Adjusted for gender & $R=0.440$ & $R=-0.181$ & $R=0.856$ \\
Adjusted for gender and BMI & $P=0.001$ & $P=0.209$ & $P<0.001$ \\
& $P=0.456$ & $R=-0.160$ & $R=0.696$ \\
& $P<0.001$ & $P=0.272$ & $P<0.001$
\end{tabular}

leptin, where there was an obvious relationship between fasting glucose levels and these adipocytokines, no such relationship was observed with adiponectin. Since our study had a relatively small number of subjects it is possible that with a larger number of subjects the correlation between adiponectin and insulin resistance may have achieved statistical significance. However, our data clearly demonstrate that insulin resistance is more tightly correlated with circulating resistin and leptin than adiponectin levels.

Resistin rather than adiponectin appeared to be a more important determinant of insulin resistance in our study. Hulver et al. (17) recently demonstrated that exercise training-induced enhancement of insulin sensitivity was not accompanied by changes in adiponectin levels. The limited role of adiponectin in enhancement of insulin action would be consistent with the recently reported studies with adiponectinnull mutant mice, which demonstrate that adiponectin deficiency itself results in no insulin resistance or glucose intolerance (18) or only moderate insulin resistance and mild glucose intolerance rather than type 2 diabetes $(19,20)$.

Of interest was the observation that leptin levels correlated strongly with insulin resistance as measured by HOMA-R. This correlation remained highly significant even after correcting for gender and BMI. While previous reports have indicated a relationship between leptin levels and insulin resistance, this relationship has been considered by some to be due to increased fat mass (21). Other investigators have demonstrated both in experimental animals and in human subjects that the association between insulin resistance and leptin levels may be independent of body fat mass $(22,23)$. Leptin can also inhibit insulin-stimulated glucose uptake in cultured rat skeletal muscle cells (24).

In summary, we have provided evidence that resistin levels correlate with insulin resistance in non-diabetic subjects. This association is less marked than that seen for leptin and insulin resistance but stronger than the association between adiponectin and insulin resistance.

\section{Acknowledgements}

This research was supported by a grant from the Canadian Institutes for Health Research. J V S is a recipient of a Canadian Diabetes Association postdoctoral award. L J M is a recipient of an endowed Research Professorship in Metabolic Diseases.

\section{References}

1 Yamashita S, Nakamura T, Shimomura I, Nishida M, Yoshida S, Kotani $\mathrm{K}$ et al. Insulin resistance and body fat distribution. Diabetes Care 199619 287-291.

2 Steppan CM, Bailey ST, Bhat S, Brown EJ, Banerjee RR, Wright CM et al. The hormone resistin links obesity to diabetes. Nature 2001 $409307-312$

3 Lehmann JM, Moore LB, Smith-Oliver TA, Wilkison WO, Willson TM \& Kliewer SA. An antidiabetic thiazolidinedione is a high affinity ligand for peroxisome proliferator-activated receptor gamma (PPAR-gamma). Journal of Biological Chemistry $1995 \mathbf{2 7 0}$ $12953-12956$

4 Yamauchi T, Kamon J, Waki H, Terauchi Y, Kubota N, Hara K et al. The fat-derived hormone adiponectin reverses insulin resistance associated with both lipoatrophy and obesity. Nature Medicine $20017941-946$.

5 Maeda N, Takahashi M, Funahashi T, Kihara S, Nishizawa H, Kishida $\mathrm{K}$ et al. PPARgamma ligands increase expression and plasma concentration of adiponectin, an adipose-derived protein. Diabetes 200150 2094-2099.

6 Ceddia RB, Koistinen HA, Zierath JR \& Sweeney G. Analysis of paradoxical observations on the association between leptin and insulin resistance. FASEB Journal 200216 1163-1176.

7 Friedman JM \& Halaas JL. Leptin and the regulation of body weight in mammals. Nature 1998395 763-779.

8 Mathews DR, Hosker JP, Rudenski AS, Naylor BA, Treacher DF \& Turner RC. Homeostasis model assessment: insulin resistance and $\beta$-cell function from fasting plasma glucose and insulin concentration in man. Diabetologia $1985 \mathbf{2 8} 412-419$.

9 McTernan CL, McTernan PG, Harte AL, Levick PL, Barnett AH \& Kumar S. Resistin central obesity and type 2 diabetes. Lancet 2002 $35946-47$

10 McTernan MG, McTernan CL, Chetty R, Jenner K, Fisher FM, Lauer MN et al. Increased resistin gene and protein expression in human abdominal adipose tissue. Journal of Clinical Endocrinology and Metabolism 200287 2407-2410.

11 Engert JC, Vohl MC, Williams SM, Lepage P, Loredo-Osti JC, Faith J et al. $5^{\prime}$ flanking variants of resistin are associated with obesity. Diabetes 200251 1629-1634.

12 Wang H, Chu WS, Hemphill C \& Elbein SC. Human resistin gene: molecular scanning and evaluation of association with insulin sensitivity and type 2 diabetes in Caucasians. Journal of Clinical Endocrinology and Metabolism 200287 2520-2524.

13 Weyer C, Funahashi T, Tanaka S, Hotta K, Matsuzawa Y, Pratley RE et al. Hypoadiponectinemia in obesity and type 2 diabetes: close association with insulin resistance and hyperinsulinemia. Journal of Clinical Endocrinology and Metabolism 200186 $1930-1935$.

14 Stefan N, Bunt JC, Salbe AD, Funahashi T, Matsuzawa Y \& Tataranni PA. Plasma adiponectin concentrations in children: relationship with obesity and insulinemia. Journal of Clinical Endocrinology and Metabolism $2002874652-4656$.

15 Yu JG, Javorschi S, Hevener AL, Kruszynska YT, Norman RA, Sinha $\mathrm{M}$ et al. The effect of thiazolidinediones on plasma adiponectin levels in normal, obese, and type 2 diabetic subjects. Diabetes $2002512968-2974$.

16 Matsubara M, Maruoka S \& Katayose S. Inverse relationship between plasma adiponectin and leptin concentrations in normal-weight and obese women. European Journal of Endocrinology 2002 147 173-180.

17 Hulver MW, Zheng D, Tanner CJ, Houmard JA, Kraus WE, Slentz CA et al. Adiponectin is not altered with exercise training despite enhanced insulin action. American Journal of Physiology. Endocrinology and Metabolism 2002283 E861-E865. 
18 Ма K, Cabrero A, Saha PK, Kojima H, Li L, Chang B et al. Increased $\beta$-oxidation but no insulin resistance or glucose intolerance in mice lacking adiponectin. Journal of Biological Chemistry $200227734658-34661$.

19 Kubota N, Terauhi Y, Kubota T, Moroi M, Matsui J, Eto K et al. Disruption of adiponectin causes insulin resistance and neointimal formation. Journal of Biological Chemistry $2002 \mathbf{2 7 7}$ 25863-25866.

20 Maeda N, Shimomura I, Kishida K, Nishizawa H, Matsuda M, Nagaretani $\mathrm{H}$ et al. Diet-induced insulin resistance in mice lacking adiponectin/ACRP30. Nature Medicine 20028 731-737.

21 Cnop M, Landchild MJ, Vidal J, Havel PJ, Knowles NG, Carr DR et al. The concurrent accumulation of intra-abdominal and subcutaneous fat explains the association between insulin resistance and plasma leptin concentrations: distinct metabolic effects of two fat compartments. Diabetes $2002 \quad 51$ 1005-1015.
22 Fischer S, Hanefeld M, Haffner SM, Fusch C, Schwanebeck U, Kohler $\mathrm{C}$ et al. Insulin-resistant patients with type 2 diabetes mellitus have higher serum leptin levels independently of body fat mass. Acta Diabetologica 200239 105-110.

23 Appleton DJ, Rand JS \& Sunvold GD. Plasma leptin concentrations are independently associated with insulin sensitivity in lean and overweight cats. Journal of Feline Medicine and Surgery 20024 83-89.

24 Sweeney G, Keen J, Somwar R, Konrad D, Garg R \& Klip A. High leptin levels acutely inhibit insulin-stimulated glucose uptake without affecting glucose transporter 4 translocation in 16 rat skeletal muscle cells. Endocrinology 2001142 4806-4812.

Received 11 November 2002

Accepted 17 July 2003 